\title{
Centro-dia para Idosos: afeto positivo como potência de ação e de fortalecimento de vínculos
}

Day Center for the Elderly: positive affect as a power of action and strengthening of bonds

Centro de día para ancianos: afecto positivo como poder de acción y fortalecimiento de lazos

Wellington da Silva Oliveira Thaís Bento Lima da Silva

RESUMO: Este estudo, descritivo e observacional, objetivou apresentar o Centro-dia para Idosos, o perfil dos usuários e a aplicabilidade da Teoria dos Afetos como potência de ação e fortalecimento de vínculos. Trata-se de um equipamento público de curta permanência para idosos em situação de vulnerabilidade social e com dependência, que têm familiares. Nota-se nas visitas domiciliares de inserção dos idosos que suas situações se traduzem em isolamento, confinamento, abandono, maustratos, negligência, preconceito, discriminação, sujeição, pobreza afetiva, dependência, fragilidade de vínculos familiares e comunitários. Após acesso ao serviço e intervenções, se observa, nos idosos, melhora na autoestima, afetividade, autonomia, independência, convivência e fortalecimento de vínculos.

Palavras-chave: Centro-dia para Idosos; Afeto positivo; Potência. 
ABSTRACT: This descriptive and observational study aimed to present the Day Center for the Elderly, the profile of users, and the applicability of the theory of positive affects as a power of action and strengthening of bonds. The Day Center for the Elderly is a short-term public resource for the elderly who have family members during situations of social vulnerability and dependency. It is noted in home visits of the elderly that their situations can translate into isolation, confinement, abandonment, abuse, neglect, prejudice, discrimination, subjection, affective poverty, dependence, and fragility of family and community bonds. After access to the services and interventions, we observed an improvement in self-esteem, affectivity, autonomy, independence, coexistence and strengthening of bonds.

Keywords: Day Center for the Elderly; Positive affect; Power.

RESUMEN: Este estudio descriptivo y observacional tuvo como objetivo presentar el Centro-Día para Ancianos, el perfil de los usuarios y la aplicabilidad de la teoría de los afectos positivos como potencia de acción y de fortalecimiento de lazos. Es una instalación pública a corto plazo para ancianos en situaciones de vulnerabilidad social y dependencia, que tienen familiares. Se observa en las visitas domiciliarias de inserción de ancianos que sus situaciones se traducen en aislamiento, encierro, abandono, maltrato, negligencia, prejuicio, discriminación, sujeción, pobreza afectiva, dependencia, fragilidad de los lazos familiares y comunitarios. Después del acceso al servicio y las intervenciones, se observa en los ancianos una mejora en la autoestima, afectividad, autonomía, independencia, convivencia y fortalecimiento de lazos.

Palabras clave: Centro-Día para Ancianos; Afecto positivo; Potencia.

\section{Introdução}

A população idosa é definida a partir dos 60 anos de idade em países em desenvolvimento, como é o caso do Brasil, e 65, em países desenvolvidos (Organização das Nações Unidas [ONU], 1982). Com o avançar da ciência e da tecnologia, a expectativa de vida da sociedade brasileira tem aumentado cada vez mais. Em 1940 a esperança de vida era de 45,5 anos, e passou em 2016 para 75,8 anos. A projeção da longevidade é que em 2060 será de 81,2 anos; e a população de 65 anos e mais passará a compor $25,5 \%$ da população geral, ou seja, um a cada quatro brasileiros será idoso na transição demográfica (Instituto Brasileiro de Geografia e Estatística [IBGE], 2017, 2018). 
É neste cenário do crescente e contínuo número de idosos que, por meio de movimentos sociais, surgem novas políticas públicas, para esta população, que demanda necessidades específicas e diversas. A proposição de abertura de Centros-dia para Idosos (CDI) foi exposta ao Conselho Municipal de Assistência Social (COMAS) do estado de São Paulo, que aprovou por meio da Resolução n. ${ }^{\circ} 836$ de 29 de julho de 2014, fazendo parte da Secretaria da Assistência e Desenvolvimento Social - SMADS (Resolução n. ${ }^{\circ}$ 836, 2014; Romualdo, 2017). O CDI é recente e teve o primeiro serviço implantado em janeiro de 2015, no bairro do Bom Retiro em São Paulo. Atualmente são 16 centros inaugurados no município em diferentes regiões para atender idosos em situação de vulnerabilidade social (SMADS, 2015, 2016).

Avaliar as condições subjetivas de bem-estar da pessoa idosa é tão importante quanto analisar suas condições objetivas de vida, pois cresceram pesquisas que indicam tal fenômeno como elementoégide às adversidades, tais como biológicas e socioeconômicas (Neri, \& Fontes, 2018). Trata-se de uma "variável de proteção em relação ao impacto negativo de vários tipos de experiências estressantes sobre a saúde dos idosos e sua longevidade" (Neri, Batistoni, \& Ribeiro, 2018, p. 1458).

O paradigma de Bem-Estar Subjetivo (BES) é complexo, e possui diversas definições, porém pesquisas empíricas apontam para características comuns, tais como o que cada pessoa sente, pensa e analisa a respeito de sua própria vida, referindo a contextos sociais e individuais (Delgado, Carvalho, \& Correia, 2019). Neri, Batistoni e Ribeiro (2018) escrevem um capítulo com base nas literaturas psicológicas, e gerontológica, sobre o constructo de bem-estar subjetivo, referindo-se a três componentes: a satisfação com a vida; os afetos positivos e negativos; e o bem-estar eudaimônico, que é o ajustamento psicológico, harmonia entre as demandas externas e as necessidades internas.

Rocha, Oliveira e Mota (2017), por meio de revisão bibliográfica sistemática, realizam investigação de evidências científicas, a respeito da associação do apoio social e BES em idosos. Os resultados apontam que o apoio eleva o bem-estar dos idosos, faz com que avaliem suas vidas de maneira mais positiva, e experimentem mais afetos positivos e menos afetos de desprazer.

Scortegagna, Pasian e Portella (2019) avaliam o BES em 70 idosos longevos com idades de 80 anos e mais, sendo 35 institucionalizados e 35 não institucionalizados, localizados em Instituição de Longa Permanência para Idosos (ILPI) e oriundos da comunidade, residentes em seus lares. O grupo institucionalizado apresentou características de piores condições funcionais, com menor nível de afeto positivo e com propensão para pior autoestima, comparado ao grupo não institucionalizado. Embora ambos os grupos indiquem experiências depressivas.

O afeto positivo é descrito como a relação prazerosa de uma pessoa com seu ambiente interno e externo, descritos frequentemente como alegria, felicidade, excitação, contentamento e entusiasmo. 
Já os afetos negativos, trata-se de uma relação desprazerosa da pessoa com o seu ambiente interno e externo, declarados como tristeza, raiva, desprazer ou medo (Neri, Batistoni, \& Ribeiro, 2018).

Nesse mesmo sentido, faz-se necessário observar não apenas as condições concretas de vida das pessoas, mas também suas condições subjetivas.

Por meio da Teoria dos Afetos do filósofo Baruch Espinosa, de 1957, Sawaia (2009) discursa sobre as paixões alegres, afetos positivos, e as paixões tristes, afetos negativos, como poder de afetar corpos, na forma de sentimentos e emoções, fazendo os sujeitos desejar, pensar e agir (Sawaia, 2009). O objetivo deste estudo é apresentar o Centro-dia para Idosos, o perfil dos usuários e a aplicabilidade da Teoria dos Afetos Positivos, como potência de ação e fortalecimento de vínculos.

\section{Métodos}

Trata-se de um estudo descritivo e observacional, realizado de agosto a outubro de 2019, com base na Teoria dos Afetos de Espinosa, e consulta de dados dos prontuários dos usuários, a fim de levantar o perfil sociodemográfico e de quadro situacional de saúde.

\section{Participantes}

Os participantes envolvidos nesta pesquisa são 30 idosos, com idades entre 62 e 92 anos, usuários na unidade e todos aqueles que se relacionam com eles, a saber: familiares dos usuários; a equipe profissional composta por gerente, assistente social, psicólogo, enfermeira, terapeuta ocupacional, nutricionista, auxiliar administrativo, dez cuidadores sociais de idosos, cozinheira, quatros agentes operacionais, para auxílio na cozinha e manutenção da higiene da instituição; e oficineiros contratados por hora/aula para atividades diárias junto aos idosos, visando a alcançar os objetivos de convivência, fortalecimento de vínculos e estimulação física e cognitiva.

\section{Local de Investigação}

O estudo foi realizado em um CDI situado na zona leste da cidade de São Paulo, um distrito que, de acordo com o Censo 2010, a população total é de 369.496, e a população idosa é cerca de 33.400, representada em 9\% (IBGE, 2010). De acordo com o Índice Paulista de Vulnerabilidade Social (IPVS), 25,6\% desta população total encontra-se em situação de alta vulnerabilidade social e com Índice de Desenvolvimento Humano Municipal (IDHM) em 0,736, inferior ao do município 
caracterizado em 0,805. O Índice de Desenvolvimento Humano (IDH) trata-se de numa escala internacional que varia de 0 a 1 , e quanto maior o índice, melhor a qualidade de vida de determinada população considerando escolaridade, renda e expectativa de vida (Secretaria Municipal de Urbanismo e Licenciamento [SMUL], 2016).

O CDI é um serviço diurno e de curta permanência, destinado a atender pessoas idosas com 60 anos e mais, em situação de vulnerabilidade social, com dependência parcial para as atividades básicas de vida diária (higiene, alimentação, mobilidade); sem comprometimento cognitivo severo, apenas leve ou moderado e que têm familiares, porém não reúnem condições de cuidar dos idosos em tempo integral no domicílio (Franciulli, Ricci, Lemos, Cordeiro, \& Gazzola, 2007; Resolução n. ${ }^{\circ}$ 283, 2005; Resolução n. $\left.{ }^{\circ} 836,2014\right)$.

O papel do CDI é prestar à pessoa idosa: proteção especial e cuidados pessoais; prevenir a segregação e a institucionalização; estimular a autonomia e a independência; promover a inclusão social por meio do fortalecimento de vínculos do idoso com a sua família e a sua comunidade, através de ações de acolhida, escuta, informação e orientação. Também visa à melhoria das condições de vida da família do idoso e diminuição da sobrecarga do cuidador, e retardar o aparecimento de doenças limitantes por meio da promoção da saúde e prevenção de doenças (Resolução n. ${ }^{\circ} 836,2014$ ).

A equipe é multiprofissional, composta por assistente social, psicólogo, enfermeira, terapeuta ocupacional e nutricionista; além da gerente de serviço, auxiliar administrativo, dez cuidadores sociais de idosos, cozinheira e quatro agentes operacionais para auxílio na cozinha e manutenção da higiene local. Também são contratados oficineiros para atividades diárias junto aos idosos (Resolução n. ${ }^{\circ} 836$, 2014).

O local oferece refeição diária e adaptada às necessidades dos usuários (Portaria SMADS n. 45, 2015; Portaria SMADS n. ${ }^{\circ}$ 4, 2016); reuniões socioeducativas e atividades socioculturais; grupos de reflexão; atividades lúdicas que possibilitem a criatividade e expressão das emoções; estimulação física e cognitiva; passeios; assistência social, psicológica, nutricional, de enfermagem e terapia ocupacional (Resolução n. ${ }^{0}$ 836, 2014).

São realizadas diversas atividades fixas e diferenciadas ao longo do mês. Quanto às diferenciadas, são intra- e extra-serviço, envolvendo familiares e comunidade, tais como ações sociais em saúde, desfile dos idosos denominado "miss e mister primavera", aniversário do serviço, datas comemorativas como dia das mães e dos pais, Natal, Ano Novo, idosos-aniversariantes. Quanto às atividades fixas, são desempenhadas por oficineiros, tais como a dança circular, tai chi chuan, ginástica adaptada, gingoterapia, musicoterapia, massoterapia individual e contação de histórias. Além de 
atividades variadas com fins diversos, elaboradas pelos cuidadores sociais e equipe multiprofissional com os idosos.

O CDI está previsto na Política Nacional do Idoso (PNI) (Lei n. ${ }^{\circ} 8.842$, 1994) e no Estatuto do Idoso (Lei n. ${ }^{\circ}$ 10.741, 2003). É um equipamento público do Sistema Único da Assistência Social (SUAS), por meio do termo de parceria e repasse de verbas da Prefeitura municipal, gestado por Organização da Sociedade Civil (OSC), antiga denominação de Organização Não Governamental (ONG), e acompanhado por meio dos gestores de parceria do Centro de Referência Especializado em Assistência Social - CREAS (Decreto n. ${ }^{\circ}$ 43.698, 2003; SMADS, 2019).

A Tipificação Nacional de Serviços Socioassistenciais categoriza o Centro-dia para Idosos como proteção especial de média complexidade (Resolução n. ${ }^{\circ}$ 109, 2009). Ele deve atender o regulamento técnico da portaria n. ${ }^{\circ}$ 5, de 11 de janeiro de 2019, da Secretaria Municipal da Saúde SMS, que estabelece as normas sanitárias mínimas de operacionalização do equipamento, público ou privado, para pessoas idosas (Portaria n. ${ }^{\circ}$ 5, 2019).

A "porta de entrada" para acesso ao serviço é via CREAS, ou em algumas regiões, por ausência deste, é via Centro de Referência em Assistência Social, CRAS; juntamente com a Avaliação Multidimensional da Pessoa Idosa na Atenção Básica (AMPI-AB), realizada na Unidade Básica de Saúde (UBS) que atende a Família. A demanda pode ser por busca ativa, incluindo denúncias, ou espontânea do próprio idoso, familiar ou rede de atendimento de outras políticas setoriais (Resolução n. $\left.{ }^{\circ} 836,2014\right)$.

\section{Resultados}

\section{Perfil sociodemográfico dos participantes}

No levantamento de perfil dos 30 usuários do CDI, identifica-se que 30\% (9) são do gênero masculino e $70 \%$ (21) do gênero feminino. A faixa de idoso mais predominante está entre septuagenários (70-79 anos) 43\% (13) e octogenários (80-89) 30\% (9); em seguida, os sexagenários (60-69) $20 \%$ (6), e nonagenários (90-99) 7\% (2). Quanto à escolaridade, 23\% (7) não foram alfabetizados; 64\% (19) apresentam de 1 a 4 anos de estudo; nenhum apresenta de 5 a 8 anos de estudo; e $4(13 \%)$ apresentam de 9 a 12 anos de estudo; ou seja, em sua maioria 87\% (26) são pessoas que têm baixa ou nenhuma escolaridade. Em relação à renda pessoal do idoso, 87\% (26) recebem um salário mínimo de 998,00 reais (Decreto $n .^{\circ} 9.661,2019$ ) e 13\% (4) recebem de mais de um salário mínimo 
até a três. Conforme o IDH, baixa escolaridade e renda influem na qualidade de vida e, consequentemente, na esperança de vida (SMUL, 2016).

Quando observada a AMPI-AB, que consiste um importante instrumento de rastreamento e diagnóstico situacional da população idosa pela Atenção Básica $(\mathrm{AB})$ e tem como interpretação "idoso saudável" (0-5 pontos), "idoso pré-frágil" (6-10 pontos) e "idoso frágil" ( $\geq 11$ pontos); identificamos no CDI que 7\% (2) são considerados idosos saudáveis (robustos); 60\% (18) idosos pré-frágeis; e 33\% (10) idosos frágeis. Tal dispositivo sugere que, quanto maior a pontuação, maior a fragilidade. Ele avalia o idoso nas dimensões da função física (atividades de vida diária), função mental (cognitiva e emocional), e função social (ambiente familiar e relações). Além de auxiliar os profissionais da saúde nas demandas e gestão do cuidado de idosos (SMS, 2016).

Quanto aos problemas de saúde, dos mais ao menos frequentes nos gerontes, estão: hipertensão arterial sistêmica 35\% (16); transtorno neurocognitivo 30\% (13); transtorno psiquiátrico 26\% (10); acidente vascular encefálico $23 \%$ (9); diabete mellitus $19 \%$ (7); convulsão $12 \%$ (4); cardiopatia $9 \%$ (3). Entre os menos frequentes estão: artrose 6\% (2); glaucoma 6\% (2); catarata 6\% (2); hipercolesterolemia 3\% (1); deficiência visual adquirida 3\% (1); deficiência auditiva adquirida 3\% (1); pneumopatia 3\% (1); osteoporose 3\% (1); esofagite 3\% (1); tendinite 3\% (1); gastroplastia 3\% (1). As Doenças Crônicas Não Transmissíveis (DCNT) são as principais causas de impactos negativos no envelhecimento da população, reverberando em incapacidade e mortalidade (Silva, Sgnaolin, Nogueira, Loureiro, Engroff, \& Gomes, 2017).

As DCNT mais comuns são a hipertensão arterial sistêmica (HAS) e diabete mellitus (DM) e são principais fatores de riscos para patologias cerebrovasculares e cardíacas, sobretudo em idosos. A multicomorbidade de DCNT aumenta o risco de mortalidade, o que a torna uma grande preocupação. As doenças mentais estão entre as mais incapacitantes, o que diminui a qualidade de vida do acometido e de seu familiar (Barreto, Carrera, \& Marcon, 2015; Silva, et al., 2017).

\section{As visitas domiciliares de inserção}

Assim que o caso da pessoa idosa é recebido pelo CREAS, ele é enviado por meio de relatório social ao CDI, para que seja feita a visita domiciliar de inserção no serviço, por meio de um dos técnicos que compõem a equipe multidisciplinar. Então, se identifica as necessidades do demandante e de sua família, apresentados os benefícios da adesão da unidade para ambos.

Nas visitas domiciliares de inserção costumeiramente nos deparamos com idosos relegados e inertes. As situações traduzem-se em isolamento, confinamento, abandono, maus-tratos, negligência, 
preconceito, discriminação, sujeição, pobreza afetiva, dependência, fragilidade de vínculos familiares e comunitários, sendo a maioria destes fenômenos já sinalizados no documento "Concepção de convivência e fortalecimento de vínculos" do Ministério do Desenvolvimento Social (MDS) como vulnerabilidades relacionais a serem intervindas para garantir segurança de convívio, aspecto da proteção social (MDS, 2017).

Nem sempre o idoso e seu familiar aceitam de prontidão o convite para frequentar o espaço e, regularmente, notam-se algumas resistências psicológicas oriundas de ansiedade, medo, dúvidas, tristeza e angústia. O que se percebe, muitas vezes, nos encontros, são sentimentos do idoso e do familiar associados à negatividade, principalmente culpa, fracasso e sensação de abandono, por não ser, ou ter sido, uma boa filha ou um bom pai, por exemplo. Aos pais ou figuras parentais se acrescenta, a seu entendimento, a falta de reconhecimento e ingratidão dos filhos pelo cuidado dispensado. Ao filho ou filha se soma a angústia de não poder retribuir o cuidado recebido pelo pai, pela mãe ou figura substituta; similarmente ao que é citado na literatura gerontológica e psicológica quanto à institucionalização do idoso (Almeida, 2018; Braga, Koike, Saad, \& Pitanga, 2019).

Em alguns casos, para os idosos e familiares, participar de um equipamento como este remete a ideias positivas que significam manter e resgatar a saúde, promover o bem-estar na convivência social, proteção e amparo ao usuário; concepção que corrobora o estudo de Simeão, et al. (2018), em que idosos frequentadores de Centros-dia apresentam maior qualidade de vida, sobretudo quando comparados aos institucionalizados.

Por outro lado, há familiares que aceitam o convite de maneira imediata, embora pouco se preocupem com o que acontecerá com o idoso no serviço. Há casos em que se recusam a conhecer o local, participar de reuniões e diálogos com a equipe profissional quando chamados, a grande maioria relacionados a vínculos fragilizados ou rompidos com o idoso, advindos de histórias de vidas sofridas e complexas.

Por vezes, preliminarmente, familiares e idosos confundem o serviço de curta permanência com as instituições de longa permanência, local de moradia, ainda fortemente associada a um asilo, ideia cristalizada que passa pelo imaginário social como um lugar de pessoas improdutivas, asiladas, não mais capazes ou úteis, com deficiência e demência (Lima, Lima, \& Oliveira, 2016). Ou ainda, há idosos que acreditam que serão obrigados a frequentar o lugar, sem que haja sua liberdade de escolha. Tal inserção a contragosto em uma instituição, Sawaia (2014) nomeou como "inclusão social perversa", quando se inclui objetivamente um sujeito numa instituição, supondo ser o melhor para ele, porém, subjetivamente, ele se sente excluído, não se sente incluído. 
Há situações em que foi preciso realizar mais de uma visita domiciliar, a fim de sensibilizar o idoso e/ou seu familiar, sobre os benefícios do equipamento para a qualidade de vida de ambos. Às vezes, sugerindo que o familiar visite o espaço junto com seu idoso, para avaliarem, ambos, o que acharam e dirimir as fantasias, os medos, as ansiedades e inseguranças. Nestes casos, inclusive, se sugere ao familiar que o idoso passe por um processo de adaptação, frequentando meio período nos primeiros dias; em igual forma se recomenda ao idoso. Algumas vezes, o próprio idoso chega a relatar que não participará todos os dias; fala também colocada pelo familiar em relação ao proponente.

\section{Discussão}

Esta pesquisa apresenta o Centro-dia para Idosos, o perfil dos usuários e a aplicabilidade da teoria dos afetos positivos como potência de ação e fortalecimento de vínculos, por meio de situações empíricas observadas ao longo de três meses. Nesse intuito, discutiremos, a seguir, a definiçãa de afeto para alguns pesquisadores e, por fim, para o filósofo Espinosa, através da socióloga Bader Sawaia, que entendem a afetividade como ética e política, pois conduzem as atitudes humanas. Assim, a pesquisa se propõe a apresentar o quanto os afetos potencializam ou despotencializam a ação de um sujeito, o que o leva a atuar de maneira negativa ou positiva em seu contexto social.

\section{Afetos positivos: afetação de corpos}

Alguns autores definem afeto com sinônimo de afetividade; outros compreendem o afeto como um conceito mais amplo, tanto de ações ou reações emocionais e sentimentais positivas ou negativas, em que a afetividade está inserida em sentido positivo.

Para Diniz (2017), o afeto é entendido como vivências de emoções e sensações físicas, que ele define como comoções somáticas, ou seja, aquilo que se experimenta no corpo. Em Benvenuti, Oliveira e Lyle (2017), o afeto e a afetividade são entendidos como similares, envolvem as relações humanas na forma de motivação, sentimentos e ânimo.

Deleuze e Guattari (1992), baseando-se na Teoria dos Afetos do filósofo Espinosa, definem afeto como simpático ou antipático, e descrevem o afeto como relações energéticas. Segundo eles, a maneira como somos afetados pode aumentar ou diminuir nossa maneira de agir. Sawaia (2009), seguindo a mesma filosofia, define o afeto como afetação, ou seja, a capacidade de afetarmos alguém ou sermos afetados por alguém, de maneira positiva ou negativa. 
Em Sawaia (2009), baseada na teoria dos afetos do filosofo Espinosa, define-se o afeto como afetação, ou seja, a capacidade de afetarmos alguém ou sermos afetados por alguém, de maneira positiva ou negativa.

$\mathrm{O}$ afeto de estímulos internos e externos implica numa via de não mão dupla entre o afetar e o ser afetado, numa relação recíproca, dialogal. Algo que se passa de um sujeito para o outro, no ato com o outro, em mútuos afetos que emergem desse encontro. Trata-se de um corpo modificado o tempo todo na relação com afeto. Um trânsito de afetos que vão e vem e se configuram em mudanças.

Os afetos não são estados psicológicos ou constructos linguísticos, mas condição e fundamentos do ser e existir. A relação entre as ameaças decorrentes da desigualdade social e respostas de afeto dos que se assujeitam denomina-se "sofrimento ético-político", diferentemente do "sofrimento ontológico", ao qual todos os sujeitos estão submetidos e a quais se somam (Sawaia, 2009). Razão pelo que, nas visitas domiciliares de inserção, constantemente nós, profissionais, encontramos idosos em condições de isolamento, confinamento, abandono, maus-tratos, negligência, preconceito, discriminação, sujeição, pobreza afetiva, dependência, fragilidade de vínculos familiares e comunitários.

\section{Afetos positivos: potencializadores de ação e de fortalecimento de vínculos}

O neoliberalismo, em sua lógica mercadológica e competitiva, com seus rituais opressivos, gera os corpos dos sujeitos, ideias, sofrimentos, afetos e desejos, em que o governo se mescla ao meio individualista e utilitarista, e o bem-estar individual passa a ocupar o lugar do bem comum. Por isso, projetos culturais e projetos sociais, na ótica dos neoliberais, são desqualificados e apontados como desperdício de verba, que gera desfalque para os cofres públicos, ou mesada para indolentes (Sawaia, Albuquerque, \& Busarello, 2018). Contexto sócio-político que colabora para a diminuição da potência de ação e fragilização ou rompimento de vínculos familiares e comunitários.

Assim que o idoso é admitido no serviço, advindo desse cenário, realiza-se um processo de acolhimento e integração com os demais idosos e a equipe de profissionais do equipamento. Então se seguem os dias e, aos poucos, o sujeito recém-chegado vai interagindo e participando cada vez mais das atividades propostas, cada qual em seu ritmo e seu tempo.

A realidade é que nem sempre nos deparamos com um estereótipo de idoso nos afetando positivamente, como aquele "velhinho bonzinho" presente, muitas vezes, como um ideal do senso comum. 
Às vezes, o encontro com o idoso é permeado pelo seu antagonismo, pessimismo, sentimento de raiva, de desprezo, da inveja, ou do ressentimento; resultado de uma história de vida sofrida e de vulnerabilidades sociais, reproduzindo, muitas vezes, as relações familiares e sociais conflituosas, no serviço.

O cotidiano na unidade é marcado pelo encontro com o afeto positivo dispensado pelos demais idosos e profissionais na lide diária, que acontece um processo transformador na vida do sujeito, refletindo inclusive em seu seio familiar, com falas como: "Ele está outra pessoa agora, mais feliz, mais carinhoso e não quer perder um dia sequer deste serviço"; ou ainda: "Ela fala que não pode faltar para não perder a vaga e, às vezes, acorda sábado ou domingo, querendo vir para o serviço". Estas palavras apontam para a construção e fortalecimento dos vínculos com os demais idosos, profissionais e respectivos familiares.

É na relação diária dos profissionais com os idosos que a afetação positiva acontece por meio da escuta atenta, do cuidado, do toque, e do gesto afável, do sentir, do se ater aos detalhes, da suspensão de sua opinião e dos preconceitos, da paciência, do silêncio, da fala, do divertimento, da risibilidade sadia, do verdadeiro encontro, que acontece no tempo e no espaço, ou seja, do acolhimento com dignidade. A que, por sua vez, os idosos respondem igualmente, e com muita gratidão.

Não raramente, em meio aos nossos encontros esperados ou inesperados com os familiares dos idosos, eles verbalizam: "Quando eu for idoso, eu quero vir para cá também; os idosos aqui são muito bem tratados por vocês", e ainda "Vocês tratam os idosos com muito carinho e atenção, percebo minha mãe cada dia melhor”. Conceito de melhora frequentemente atribuído às questões físicas, cognitivas e relacionais dos usuários no serviço e no núcleo familiar, caracterizando cenas de potência de ação por meio do afeto positivo.

Há também relatos costumeiros dos idosos, tais como: "Aqui eu me sinto melhor que em casa; vocês tratam a gente com carinho, amor, com respeito"; ou ainda "É uma pena que aqui não funcione aos finais de semana, fazer o que, né?", fala de uma pessoa idosa que resistiu diversas vezes a nosso convite para frequentar o serviço, mesmo estando em condições precárias de cuidado e isolamento social, mas que um dia resolveu ir conhecer sem obrigação de permanecer, depois de tantas sensibilizações nas visitas de inserção em domicílio. Pouco tempo depois de inserida, a fala de uma das filhas e do esposo foi: "Ela mudou muito, está mais atenta, antes ela nem queria vir, e agora não quer faltar de jeito nenhum”. 
Um dos objetivos basilares da unidade é a promoção da saúde e o empoderamento ${ }^{1}$ dos usuários, advindos de um contexto de vulnerabilidade social, para alcançar o protagonismo ${ }^{2}$ social e político. A palavra vulnerabilidade, do latim vulnerare $=$ ferir, expressa a susceptibilidade do sujeito a ser ferido (Neri, 2014). Tal concepção é multidimensional e refere-se a uma condição de fragilidade material ou moral de atores sociais, indivíduos ou grupos, diante de riscos produzidos pelo contexto econômico-social, tais como a miséria, a educação deficitária, a baixa renda e a sua localização geográfica em péssimas condições. O termo não diz respeito apenas ao precário ou ausente acesso da renda, mas também às fragilidades de vínculos afetivos-relacionais e disparidade de ingresso aos serviços públicos e bens (Carmo, \& Guizard, 2018).

\section{Grupos socioeducativos: espaço afetivo potencial de ação e de fortalecimento de vínculos}

Semanalmente, como um dos métodos de convivência social, potência de ação e de fortalecimento de vínculos, no serviço se organizam grupos socioeducativos ${ }^{3}$ temáticos com os idosos. Espaço que favorece e fomenta o acolhimento da fala, a escuta e o trânsito de afetos negativos e positivos, colaborando para a construção da afetividade, base da organização social e do bem-estar coletivo (Sawaia, 2009).

Por meio destes encontros, observa-se a relação dialogal; resgate de histórias; troca de experiências, demandas e possibilidades; expressão dos afetos; construção de projetos pessoais e sociais; desenvolvimento da autoestima; resgate ou fortalecimento da identidade pessoal e social; e reparação ou minimização dos efeitos de violências e abusos diversos sofridos. Contexto que proporciona a emergência e a evolução de competências e oportunidades para a autonomia, se relacionar e conviver em grupo e com as diferenças.

Em uma das tramas do grupo socioeducativo, durante a discussão, uma pessoa idosa recémchegada verbaliza: "Eu não quero dar trabalho... quando a gente fica velho não serve pra mais nada, só enche o saco, dá trabalho, não sou mais feliz como já fui, queria ser feliz novamente”.

\footnotetext{
${ }^{1}$ Termo traduzido do inglês, empowerment. No Brasil, Paulo Freire (1921-1997) foi pioneiro no uso da palavra em sentido políticosocial. Para ele, a evolução da consciência genuína à consciência crítica leva à transformação da sociedade, por meio da chamada práxis, isto é, reflexão-ação-reflexão. Tal concepção consiste no indivíduo ou grupo social que, empoderado, por sua liberdade, supere os estados de subordinação e possa romper a dicotomia oprimido-opressor. Nesse sentido, emerge uma postura receptiva ou reativa, levando em conta seu potencial pessoal e social (Freire, 1979, 1996; A. M. Freire, 2006).

${ }^{2}$ Conceito em que a acepção é relacional, quando os atores assumem o seu papel principal e ativo, de modo consciente e responsável, na dimensão pessoal e plural de convivência com diferentes sujeitos, de maneira dialógica, engajados num acontecimento, na comunidade em que pertence. O protagonismo é um antídoto oponente do isolamento social e da indiferença, com a revelação ou retomada de uma energia que afeta o agir coletivo de poder mudar a realidade social e assumir o controle do próprio destino (Farias, 2017).

${ }^{3}$ Palavra que se refere à educação social e está inseparavelmente conectada à exclusão social, sendo decorrente dela. A educação social inversamente está voltada para a potencialização de alternativas, para todas as pessoas, independentemente do estrato social e que estão, sobretudo, em condições de vulnerabilidade social (Paula, Silva, \& Santos, 2017). De acordo com a Política Nacional de Assistência Social, ações socioeducativas, dentre elas os grupos socioeducativos, fundamentam-se numa visão participativa e dialogal, visando a desenvolver talentos e capacidades para a convivência social, protagonismo e autonomia (MDS, 2004, 2006).
}

Oliveira, W. da S., \& Lima da Silva, T. B. (2019). Centro-dia para Idosos: afeto positivo como potência de ação e de fortalecimento de vínculos. Revista Kairós-Gerontologia, 22(2), 141-159. ISSNprint 1516-2567. ISSNe 2176-901X.

São Paulo (SP), Brasil: FACHS/NEPE/PUC-SP 
Fala que reproduz o estereótipo e o preconceito da representação social da velhice e da vivência do idoso que vem de um contexto social de desvalia, impotência e subordinação, permeado por afetos negativos e que geram potência de padecimento, mantendo o sujeito sem condições de decidir sobre a própria vida e suas vontades. Discurso que carrega em seu bojo o reflexo da desigualdade social, produzindo mal-estar subjetivo como medo, humilhação e sofrimento humano, muito embora haja o desejo de recomeçar a vida e encontrar a felicidade (Sawaia, 2009).

Em outro episódio no grupo, ao final do encontro, uma idosa comenta: "Este grupo aqui é muito bom, eu me sinto cada vez melhor, aprendo e ensino a cada dia, sinto que não estou sozinha, tenho pessoas que gosto de conversar, que tenho carinho e que me querem bem, eu já sofri muito, já me senti muito sozinha com quem não vale nada, aqui (no serviço) eu estou revivendo”. E, ainda em outra cena um idoso chora ao falar da ausência de sua filha no convívio diário, pois reside longe, e outro participante se levanta para dar um abraço e diz: "Vai ficar tudo bem, aqui temos uns aos outros, minha filha também mora longe, mas sempre peço para meu filho ligar para ela para conversar”. Como aponta Sawaia, Albuquerque e Busarello (2018) os afetos positivos são a base da subjetividade, de nossas ações e pensamentos. A potência de vida precisa do outro para se fortalecer e, nesta união, é quando a logicidade dos afetos concede a assimilação da generosidade e amizade como peça benéfica, que se revela e amplia o impulso para existir e atuar politicamente.

Os "bons encontros", assim nomeados por Espinosa, referem-se ao resultado das relações caracterizadas pelo empoderamento; a justiça e a autonomia aumentam a potência de ação dos corpos; ao contrário, os "maus encontros" são conformados em servidão, injustiça e heteronomia tornando-se potência de padecimento, de reação e não de ação, reduzindo esforços de perseverar na própria existência (Sawaia, 2009).

Assim, os profissionais da unidade, por meio da Teoria dos Afetos se faz presente junto aos idosos, convocando-os ao protagonismo de suas vidas, de maneira social-política, na construção e reconstrução de sua realidade, diante da tessitura social antagonista. E, instrumentalizando os profissionais cuidadores sociais do núcleo, diante da trama, a serem coadjuvantes afetivos e atentos à dimensão subjetiva dos gerontes, considerando sua capacidade e liberdade de fazer escolhas.

\section{Considerações finais}

É na afetação positiva constante que observamos, nos idosos, a melhora na autoestima, da afetividade, da autonomia, da independência, na convivência e no fortalecimento de vínculos familiares e comunitários. 
Muito tem a se contribuir com a psicologia social neste serviço, pois, como salienta Sawaia (2009), na análise das questões sociais, ela tem um saber militante para atuar em políticas públicas de assistência social e saúde, movimentos sociais, comunidade e outras ações de configuração coletiva.

A população está envelhecendo cada vez mais, e é importante que esta longevidade ocorra com qualidade de vida, de maneira afetiva, para motivar as pessoas a se munirem com ferramentas, de modo que possam tomar as rédeas de suas vidas. Precisamos somar esforços por meio dos afetos positivos, pois, como descreve Sawaia (2009), o individual não tem força social, e a afetividade é a base de sua organização.

Estamos em meio a uma cultura que está no caminho da mudança de paradigmas do "ser pessoa idosa" ainda excluída e desvalida, associada mais a aspectos negativos que positivos. Também não podemos nos esquecer dos gerontólogos e dos cuidadores de idosos que estão em busca de legitimação de suas práticas profissionais já existentes e atuantes, que fazem grande diferença na vida dos idosos e da sociedade como um todo, por sua especificidade de atuação para este público com demandas bastante peculiares.

Este público tem necessidades, mas também possibilidades e capacidades a desenvolverem, acima de tudo, com grande vantagem em um espaço afetuoso, pois, para o filósofo Espinosa, paixões tristes, afetos negativos, geram potência de padecimento e paixões alegres, afetos positivos, potência de agir. É neste interespaço e interjogo que os idosos podem alcançar a promoção da saúde, transmutando da vulnerabilidade ao protagonismo social de suas vidas.

Sobre o Centro-dia para Idosos, por ser uma política pública recente, existem poucos estudos na literatura que versem sobre a temática, sobretudo, quanto aos afetos que perpassam neste campo de atuação com os idosos. Assim, se sugerem pesquisas voltadas para a aplicabilidade da Teoria dos Afetos Positivos também junto aos familiares destes idosos por meio de ações socieducativas, num espaço de escuta e acolhimento, já que, é para ela, que muitas vezes eles retornam ao final do dia e permanece nos finais de semana.

Para findar, valendo-nos da Teoria dos Afetos, citamos um trecho que descreve a alegria ou tristeza, que resulta do afeto, colaborando para o aumento ou a diminuição da potência de ação dos nossos corpos por meio dos encontros e relações que estabelecemos:

[...] somos um grau de potência, definido pelo poder de afetar e ser afetado [...]. Só através de encontros aprendemos a selecionar o que convém com nosso corpo, o que não convém, o que com ele se compõe, o que tende a decompô-lo, o que aumenta sua força de existir, o que a diminui, o que aumenta sua potência de agir, o que a diminui, e, por conseguinte o que resulta em alegria, ou tristeza [...]. A tristeza é toda paixão 
que implica uma diminuição de nossa potência de agir; a alegria, toda paixão que aumenta nossa potência de agir (Pélbart, 2008).

\section{Referências}

Almeida, M. F. M. (2018). A culpa escondida: uma leitura analítica da culpabilidade em filhos de idosos institucionalizados. Dissertação de mestrado. Universidade de Évora, Évora, Portugal.

Barreto, M. S., Carreira, L., \& Marcon, S. S. (2015). Envelhecimento populacional e doenças crônicas: Reflexões sobre os desafios para o Sistema de Saúde Pública. São Paulo, SP: PUC-SP: Revista KairósGerontologia, 18(1), 325-339. ISSNprint 1516-2567. ISSNe 2176-901X. Recuperado em 01 dezembro, 2018, de: https://revistas.pucsp.br/index.php/kairos/article/view/26092/

Benvenuti, M. F. L., Oliveira, T. P., \& Lyle, L. A. G. (2017). Afeto e comportamento social no planejamento do ensino: a importância das consequências do comportamento. Psicologia USP, 28(3), 368-377. Recuperado em 01 dezembro, 2018, de: https://doi.org/10.1590/0103-656420160135.

Braga, C., Koike, M. K., Saad, K. R., \& Pitanga, F. (2019). Idoso institucionalizado: sentimentos dos familiares em relação à institucionalização. International Journal of Health Management, 5(1), 1-13. Recuperado em 01 dezembro, 2018, de: https://www.ijhmreview.org/ijhmreview/article/ viewFile/153/92.

Carmo, M. E., \& Guizardi, F. L. (2018). O conceito de vulnerabilidade e seus sentidos para as políticas públicas de saúde e assistência social. Cadernos de Saúde Pública, 34(3), e00101417. Recuperado em 01 dezembro, 2018, de: https://doi.org/10.1590/0102-311x00101417.

Decreto n. ${ }^{\circ} 43.698$, de 2 de setembro de 2003. Regulamenta a Lei $n .^{\circ} 13.153$, de 22 de junho de 2001, que dispõe sobre a Política Pública de Atenções da Assistência Social, sem fins lucrativos, operada através de convênios no âmbito do município de São Paulo. Recuperado em 01 dezembro, 2018, de: http://legislacao.prefeitura.sp.gov.br/leis/lei-13153-de-22-de-junho-de-2001/detalhe.

Decreto n..$^{\circ}$ 9.661, de 1 de janeiro de 2019. Regulamenta a Lei ${ }^{\circ} .^{\circ} 13.152$, de 29 de julho de 2015, que dispõe sobre o valor do salário mínimo e a sua política de valorização de longo prazo. Recuperado em 01 dezembro, 2018, de: http://www.planalto.gov.br/ccivil_03/_Ato20192022/2019/Decreto/D9661.htm.

Deleuze, G., \& Guattari, F. (1992). O que é a filosofia? Bento Prado Jr. e Alberto Alonso Muñoz, Trads. Rio de Janeiro, RJ: Editora 34.

Delgado, P., Carvalho, J. M. S., \& Correia, F. (2019). Viver em acolhimento familiar ou residencial: o bem-estar subjetivo de adolescentes em Portugal. Psicoperspectivas, 18(2), 86-97. Recuperado em 01 dezembro, 2018, de: http://dx.doi.org/10.5027/psicoperspectivas-vol18-issue2-fulltext-1605.

Diniz, L. G. (2017). Derramam-se os horizontes: por uma experiência literária cinética. Ilha do Desterro, 70(2), 71-82. Recuperado em 01 dezembro, 2018, de: https://doi.org/10.5007/21758026.2017v70n2p71.

Farias, M. G. G., \& Varela, V. A. (2017). A mediação da informação e o protagonismo social: experimentando a construção de um modelo em uma comunidade brasileira. Investigación bibliotecológica,31(73), 91-110. Recuperado em 01 dezembro, 2018, de: http://www.scielo.org.mx/pdf/ib/v31n73/2448-8321-ib-31-73-00091.pdf.

Freire, A. M. (2006). Paulo Freire: uma história de vida. Indaiatuba, SP: Villa das Letras. 
Freire, P. (1979). Conscientização. São Paulo, SP: Cortez e Moraes.

Freire, P. (1996). Pedagogia da Autonomia: saberes necessários à prática educativa. (25a ed.). São Paulo, SP: Paz e Terra.

Franciulli, S. E., Ricci, N. A., Lemos, N. D., Cordeiro, R. C., \& Gazzola, J. M. (2007) A modalidade de assistência centro-dia geriátrico: efeitos funcionais em seis meses de acompanhamento multiprofissional. Ciência \& Saúde Coletiva, 12(2), 373-380. Recuperado em 01 dezembro, 2018, de: https://doi.org/10.1590/S1413-81232007000200013.

Instituto Brasileiro de Geografia e Estatística. (IBGE). (2018). Projeção da população 2018: número de habitantes do país deve parar de crescer em 2047. Recuperado de https://agenciadenoticias.ibge.gov.br/agencia-sala-de-imprensa/2013-agencia-de-noticias/releases/ 21837-projecao-da-populacao-2018-numero-de-habitantes-do-pais-deve-parar-de-crescer-em-2047.

Instituto Brasileiro de Geografia e Estatística. (IBGE). (2018). Projeção da população 2018: número de habitantes do país deve parar de crescer em 2047. Recuperado de https://agenciadenoticias.ibge.gov.br/agencia-sala-de-imprensa/2013-agencia-de-

noticias/releases/21837-projecao-da-populacao-2018-numero-de-habitantes-do-pais-deve-parar-decrescer-em-2047.

Instituto Brasileiro de Geografia e Estatística. (IBGE). Censo 2010. Recuperado de https://censo2010.ibge.gov.br/.

Lei n. ${ }^{\circ} 10.741$, de 1 de outubro de 2003. Dispõe sobre o Estatuto do Idoso e dá outras providências. Recuperado em 01 dezembro, 2018, de: http://www.planalto.gov.br/ccivil_03/leis/2003/110.741.htm.

Lei n. ${ }^{\circ} 8.842$, de 4 de janeiro de 1994. Dispõe sobre a Política Nacional do Idoso, cria o Conselho Nacional do Idoso e dá outras providências. Recuperado em 01 dezembro, 2018, de: http://www.planalto.gov.br/ccivil_03/leis/18842.htm.

Lima, L. P., Lima, M. F., \& Oliveira, W. S. (2016). Tramas e dramas: intervenção psicológica possível. In: Dias, E. T. D. M., Lima, L. P., \& Barbosa, L. M. G. (Org.). Compartilhando saberes psicológicos, filosóficos e educacionais (Cap. 6, 91-114). Jundiaí, SP: Paco.

Ministério do Desenvolvimento Social. (MDS). (2017). Concepção de convivência e fortalecimento de vínculos. Recuperado em 01 dezembro, 2018, de: http://www.mds.gov.br/webarquivos/publicacao/assistencia_social/Cadernos/concepcao_fortalecime nto_vinculos.pdf.

Neri, A. L (2014). Palavras-chave em gerontologia. (4 ed.). Campinas, SP: Alínea.

Neri, A. L., \& Fontes, A. P. (2018). Resiliência psicológica e velhice bem-sucedida. In: Freitas, E. V.

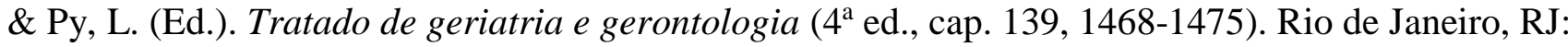
Guanabara Koogan.

Neri, A. L., Batistoni, S. S. T., \& Ribeiro, C. C. (2018). Bem-estar psicológico, saúde e longevidade. In: Freitas, E. V. \& Py, L. (Ed.), Tratado de geriatria e gerontologia (4a ed., cap. 138, 1458-1467). Rio de Janeiro, RJ: Guanabara Koogan.

Organização das Nações Unidas. (ONU). (1982). Assembleia Mundial sobre Envelhecimento: Resolução 39/125. Recuperado em 01 dezembro, 2018, de: https://nacoesunidas.org/acao/pessoasidosas/. 
Paula, E. M. A. T., Silva, L. T., \& Santos, M. A. (2017). As possíveis relações da Educação Social e da Pedagogia Social no Programa "Mais - Educação". Revista Eletrônica de Educação, 11(2), 455470. Recuperado em 01 dezembro, 2018, de: file:///C:/Users/Dados/AppData/Local/Temp/181711477-1-PB.pdf.

Pélbart, P. P. (2008). Elementos para uma cartografia da grupalidade. In: Saadi, F., Garcia, S. (Org.). Próximo ato: questões de Teatralidade Contemporânea. São Paulo, SP: Itaú Cultural, 33-37. Recuperado em 01 dezembro, 2018, de: http://eps.otics.org/material/entrada-outrasofertas/artigos/elementos-para-uma-cartografia-da-grupalidade/view.

Portaria Secretaria Municipal de Saúde [SMS] - n. ${ }^{\mathrm{S}}$ 5, de 11 de janeiro de 2019. Aprova o Regulamento Técnico que estabelece as normas sanitárias de funcionamento dos Centros-Dia para pessoas idosas, públicos ou privados. Recuperado em 01 dezembro, 2018, de: http://legislacao.prefeitura.sp.gov.br/leis/portaria-secretaria-municipal-da-saude-sms-5-de-11-dejaneiro-de-2019/consolidado.

Portaria SMADS n. ${ }^{\mathrm{O}}$ 4, de 22 de fevereiro de 2016. Retifica a Portaria n. ${ }^{\circ}$ 45/SMADS/2015, que trata de normas e recomendações técnicas para alimentação nos serviços socioassistenciais operados por meio de convênios com SMADS. Recuperado em 01 dezembro, 2018, de: http://legislacao.prefeitura.sp.gov.br/leis/portaria-sec-mun-de-assistencia-e-desenvolvimento-social4-de-23-de-fevereiro-de-2016/consolidado.

Portaria SMADS n. ${ }^{\circ}$ 45, de 17 de dezembro de 2015. Trata de normas e recomendações técnicas para alimentação nos serviços socioassistenciais operados por meio de convênio com SMADS. Recuperado em 01 dezembro, 2018, de: http://legislacao.prefeitura.sp.gov.br/leis/portaria-sec-mun-de-assistenciae-desenvolvimento-social-45-de-19-de-dezembro-de-2015.

Resolução do Conselho Municipal de Assistência Social [COMAS] - SP n. ${ }^{o} 836$ de 29 de julho de 2014. Dispõe sobre a aprovação do serviço Centro-dia para Idoso. Recuperado em 01 dezembro, 2018, de: https://www.prefeitura.sp.gov.br/cidade/secretarias/upload/assistencia_social/comas/res14/836.pdf.

Resolução n. ${ }^{\circ}$ 109, de 11 de novembro de 2009. Aprova a Tipificação Nacional de Serviços Socioassistenciais. Recuperado em 01 dezembro, 2018, de: http://www.mds.gov.br/webarquivos/legislacao/assistencia_social/resolucoes/2009/Resolucao\%20C NAS\%20no\%20109-\%20de\%2011\%20de\%20novembro\%20de\%202009.pdf.

Resolução RDC n. ${ }^{\circ}$ 283, de 25 de setembro de 2005. Regulamenta as Instituições de Longa Permanência Para Idosos. Recuperado em 01 dezembro, 2018, de: http://bvsms.saude.gov.br/bvs/saudelegis/anvisa/2005/res0283_26_09_2005.html.

Rocha, L. F. D., Oliveira, E. F., \& Mota, M. M. P. E. (2017). Relationship between social support and subjective well-being in older people: systematic review. Revista Brasileira em Promoção da Saúde, 30(4), 1-13. Recuperado em 01 dezembro, 2018, de: DOI: 10.5020/18061230.2017.6472.

Romualdo, C. R. L. (2017). Implantação dos Centros Dia para Idosos no município de São Paulo. 2017. Secretaria Municipal da Assistência e Desenvolvimento Social. Prefeitura da cidade de São Paulo. Recuperado em 01 dezembro, 2018, de: http://www.preferitura.sp.gov.br/artigos.

Sawaia, B. B. (2009). Psicologia e desigualdade social: uma reflexão sobre a liberdade e transformação social. Psicologia e Sociedade, 21(3), 364-372. Recuperado em 01 dezembro, 2018, de: http://www4.pucsp.br/nexin/artigos/download/psicologia-e-desigualdade-social.pdf.

Sawaia, B. B. (Org). (1999). As artimanhas da exclusão: análise psicossocial e ética da desigualdade social. Petrópolis, RJ: Vozes. 
Secretaria Municipal da Assistência e Desenvolvimento Social (SMADS). (2015). SMADS inaugura Centro-dia para Idosos. Recuperado em 01 dezembro, 2018, de: http://www.prefeitura.sp.gov.br/cidade/secretarias/assistencia_social/noticias/?p=202755.

Secretaria Municipal da Assistência e Desenvolvimento Social (SMADS). (2016). Prefeitura atende mais de 14.600 idosos em equipamentos sociais instalados em todas as regióes da capital. Recuperado em 01 dezembro, 2018, de: http://www.prefeitura.sp.gov.br/cidade/secretarias/assistencia_social/ noticias/?p=285241.

Secretaria Municipal da Assistência e Desenvolvimento Social (SMADS). (2019). Manual de parcerias da SMADS. Recuperado em 01 dezembro, 2018, de: https://www.prefeitura.sp.gov.br/cidade/secretarias/assistencia_social/legislacao/index.php?p=263050.

Secretaria Municipal da Saúde (SMS). (2016). Documento norteador: Unidade de Referência à Saúde do Idoso. São Paulo; 2016. Recuperado de http://www.prefeitura.sp.gov.br/cidade/secretarias/upload/saude/documentonorteador\%20URSIversa ofinal09012017.pdf.

Secretaria Municipal de Urbanismo e Licenciamento (SMUL) (2016). Arquivos Planos Regionais. Recuperado em 01 dezembro, 2018, de: https://gestaourbana.prefeitura.sp.gov.br/arquivos-planosregionais/.

Silva, A. R., Sgnaolin, V., Nogueira, E. L., Loureiro, F., Engroff, P., \& Gomes, I. (2017). Doenças crônicas não transmissíveis e fatores sociodemográficos associados a sintomas de depressão em idosos. Jornal Brasileiro de Psiquiatria, 66(1), 45-51. Recuperado em 01 dezembro, 2018, de: https://doi.org/10.1590/0047-2085000000149.

Simeão, S. F. A. P., Martins, G. A. L., Gatti, M. A. N., Conti, M. H. S., Vitta, A., \& Marta, S. N. (2018). Estudo comparativo da qualidade de vida de idosos asilados e frequentadores do centro dia. Ciência \& Saúde Coletiva,23(11), 3923-3934. Recuperado em 01 dezembro, 2018, de: https://doi.org/10.1590/1413-812320182311.21742016.

Teixeira, C. R., Scortegagna, S. A., Pasian, S. R., \& Portella, M. R. (2019). Bem-Estar Subjetivo de Longevos. Avaliação Psicológica, 18(1), 86-95. Recuperado em 01 dezembro, 2018, de: DOI: http://dx.doi.org/10.15689/ap.2019.1801.13512.10.

Recebido em 09/12/2019

Aceito em 30/12/2019

\section{Conflito de interesses}

O estudo não revelou conflitos de interesses. 
Wellington da Silva Oliveira - Bacharel em Psicologia, Universidade Nove de Julho, Especialização em Saúde Pública, Centro Universitário São Camilo, e Especialização em Docência do Ensino Superior e Especialização em Gênero e Sexualidade, Faculdade Dom Alberto. Atuante como Psicólogo Clínico e trabalhando como Psicólogo Social em um Centro-dia para Idosos.

E-mail: wlg_silva@live.com

Thaís Bento Lima da Silva - Mestra e Doutora pelo Programa de Neurologia Cognitiva da Faculdade de Medicina da Universidade de São Paulo. Coordenadora da Pós-Graduação em Gerontologia, da Faculdade Paulista de Serviço Social (FAPSS). Docente do Curso de Graduação em Gerontologia da EACH-USP

E-mail: gerontologathais@gmail.com 